Departamento de Historia Universidad de Santiago de Chile

Revista de Historia Social

y de las Mentalidades

Volumen 25, N², 2021: 5-42

Issn Online: 0719-4749

\title{
CREAR DOS, TRES, MUCHOS CHE: LA INTERNACIONALIZACIÓN DE LAS IDEAS REVOLUCIONARIAS A TRAVÉS DE ERNESTO GUEVARA EN LA REVISTA TRICONTINENTAL (1967-1990)*
}

\author{
CREATING TWO, THREE, MANY CHE: THE INTERNATIONALIZATION \\ OF REVOLUTIONARY IDEAS THROUGH ERNESTO GUEVARA IN \\ TRICONTINENTAL JOURNAL (1967-1990)
}

\author{
DRA. PATRICIA CALVO** \\ Universidad de Cádiz \\ Cádiz, España \\ Email: patricia.calvo@uca.es \\ Id-ORCID: 0000-0002-4644-0285
}

\begin{abstract}
RESUMEN
Ernesto Guevara constituyó el principal catalizador del ideario revolucionario tras el año 1959, con la publicación de sus obras y la asunción del «foquismo» como doctrina y práctica en los movimientos de izquierda de la segunda mitad del siglo XX. A partir de su muerte en Bolivia en 1967, se constató el fracaso de este modelo que, no obstante, se fue adaptando para servir de concitador de voluntades alrededor del mundo. Se toma así la desaparición física del Che como punto de partida para analizar el uso de sus palabras y su imagen en la revista Tricontinental, donde ocupó un lugar preponderante desde la primera publicación del suplemento especial con su texto "Crear dos, tres... muchos Vietnam" en abril de 1967.
\end{abstract}

Palabras clave: Ernesto Che Guevara; Tricontinental; Revolución Cubana; nueva izquierda

\begin{abstract}
Ernesto Guevara was the main agent of the revolutionary ideology after 1959 , resulting the publication of his works and the assumption of "foquismo" as doctrine and practice in the leftwing movements in the second half of the 20th century. His death in Bolivia in 1967 meant the failure of this model. However, it was adapted to serve as an unifying agent around the world. Thus, the physical disappearance of Che is taken as a starting point to analyse the use of his words and his image in the Tricontinental magazine, where he occupied a prominent place from the first publication with his text "Create two, three ... many Vietnam" in April 1967.
\end{abstract}

Keywords: Ernesto Che Guevara; Tricontinental Journal; Cuban Revolution; New Left

* $\quad$ Recibido: 11 de mayo de 2021; Aceptado: 28 de julio de 2021.

** Este artículo se desprende de la investigación postdoctoral de la autora, referente a la transferencia de la dimensión pública revolucionaria en América Latina post 1959. 
Cómo citar: Calvo G., Patricia. (2021). "Crear dos, tres, muchos Che: La internacionalización de las ideas revolucionarias a través de Ernesto Guevara en la revista Tricontinental (1967-1990)". Revista Historia Social y de las Mentalidades, 25(2), 5-42. https://doi.org/10.35588/rhsm.v25i2.4957

\section{INTRODUCCIÓN: CONTEXTUALIZANDO}

Un compatriota de Guevara canta que "todos se compran la remerita del Che sin saber quien fue" (Johansen), en una letra que ahonda en el carácter mercadotécnico que ha adquirido la figura del guerrillero argentino, a la par que reivindica su trascendencia a través de los años con visos de inmortalidad. ${ }^{1}$ Este imaginario de prevalencia legendaria es el punto de partida del presente artículo, que plasma la construcción del uso de las palabras y la imagen de Ernesto Che Guevara tomando como fuente la revista Tricontinental, una publicación nacida en 1967 en La Habana y que, según Dirk Kruijt, "cultiva su legado político" (206). Este órgano -editado por el Secretariado Ejecutivo de la Organización de Solidaridad de los Pueblos de África, Asia y América Latina (OSPAAAL) - lo situamos dentro de "las publicaciones de la Nueva Izquierda que contaron con difusión internacional y que contribuyeron a difundir versiones del marxismo opuestas a las defendidas por la Unión Soviética" (Martín y Rey 20), marco que aporta el sostén teórico y metodológico al presente trabajo. Se propone así un acercamiento a Ernesto Guevara a través de las páginas de Tricontinental, comenzando con una contextualización de naturaleza temporal y de la fuente objeto de estudio, para pasar a un análisis de la revista en relación al tratamiento que recibió el Che. El objetivo es constatar si efectivamente sirvió de instrumento para la perpetuación de su legado y cómo fue la naturaleza de su difusión.

En un plano general, la conceptualización del estudio busca también desentrañar cómo se fraguó la centralidad cubana en la oleada de la Nueva Izquierda en la década de 1960, tomando la Revolución Cubana como uno de los elementos desencadenantes de dicha oleada, lo que conllevó la difusión de un marco ideológico caracterizado por las ideas de antimperialismo, liberación nacional, revolución y lucha armada (Rapoport 22). En este contexto, las revistas políticas de carácter contrahegemónico -y Tricontinental particularmente ${ }^{2}-\mathrm{se}$

1 Esta línea también se refleja extra académicamente, entre otras manifestaciones, en el documental Chevolution (López y Ziff) o en la canción de The Clap, "Che Guevara T-Shirt Wearer" (2007).

2 Otros ejemplos de esta tipología de revistas serían Punto Final (Chile), Marcha (Uruguay), Cristianismo y Revolución (Argentina), Partisans, Les Temps Modernes y Le Nouvel Observateur (Francia), Quaderni Piacentini (Italia), New Left Review (Gran Bretaña), Monthly Review (Estados Unidos) o la también cubana Pensamiento Crítico (Rey y Martín). 
toman como funcionales al crecimiento de las condiciones subjetivas de la revolución (Gilman 64) y como lugares de encuentro de los intelectuales de Nueva Izquierda a nivel global. ${ }^{3}$ El pensamiento contenido en estas publicaciones contribuyó a la construcción de una cultura política revolucionaria, así como a la difusión de un repertorio de acción propio-la lucha armada-y del antimperialismo y el socialismo como ideologías movilizadoras (Fernández G. 69). A su vez, esta propagación fue posible por la construcción de una red de publicaciones y editores de izquierda que propiciaron la transmisión del pensamiento de líderes e intelectuales revolucionarios (Martín y Rey 22-25), engranaje en el cual la revista objeto de estudio y la figura del Che desempeñaron un papel fundamental.

Como apunta Gracia Santos (44), respecto a América Latina, se cita con frecuencia al argentino Silvio Frondizi como el representante de un marxismo renovado, no estalinista, que buscaba crear nuevas agrupaciones de izquierda fuera de los partidos comunistas (PC) y del trotskismo a principios de la década de 1950. Esta posición defendía una revolución única y socialista, frente a la postura comunista de la revolución por etapas. El triunfo revolucionario cubano en 1959 dio la razón a los que concordaban con estos postulados: la posibilidad de una revolución socialista directa sin pasar por la fase de una revolución burguesa y lo erróneo de la tesis de la colaboración con las burguesías nacionales en pos de la revolución democrática. Cuba demostró que la estrategia revolucionaria a seguir no era la propugnada por los PC, de participación en elecciones y pactos con partidos burgueses, sino el enfrentamiento directo con la oligarquía y sus representantes a través de las armas. La Revolución Cubana, por tanto, fue el evento que sacudió las relaciones entre la izquierda latinoamericana, generando un debate en cuanto a la forma que debería adquirir el movimiento de transformación social. En el contexto internacional, el surgimiento de la Nueva Izquierda se vincula asimismo al ciclo movilizador de finales de la década de los sesenta. Pero este no puede ser comprendido sin el impacto que tuvieron los procesos revolucionarios y descolonizadores activos en los países del Tercer Mundo, en donde la figura del Che Guevara ejerció un rol importante. Si bien la independencia de Argelia y la guerra de Vietnam también influyeron en la eclosión de la Nueva Izquierda, el triunfo cubano fue el proceso determinante y generador de una mayor legitimización discursiva. La condición «humanista» de la Revolución Cubana (Löwy 7), su carácter socialista - pero disímil al de los países de Europa del este-, su condición antimperialista -identificando a Estados Unidos como el principal causante del subdesarrollo del Tercer Mundo-,

3 Para un debate sobre la conceptualización de Nueva Izquierda, véase Artaraz (80-93). 
el hecho de que el proceso revolucionario estuviera dirigido por una generación joven o el tipo de intelectualidad comprometida que defendía -ejemplificada en la figura del Che Guevara-, fueron factores que promovieron la atracción de la Nueva Izquierda hacia Cuba (Artaraz 91).

El punto álgido del vínculo entre la Nueva Izquierda y la Revolución Cubana se dio en la segunda mitad de la década de 1960, con la concurrencia de varios eventos, como la Primera -y única-Conferencia Tricontinental y la creación de la Organización de Solidaridad de los Pueblos de África, Asia y América Latina (OSPAAAL) en enero de 1966, la Conferencia de la Organización Latinoamericana de Solidaridad (OLAS) en agosto de 1967 o el Congreso Cultural de La Habana a principios de 1968. Junto a la propuesta teórica de Régis Debray en ¿Revolución en la revolución? y el llamamiento a desarrollar la lucha armada en diferentes países del Tercer Mundo del Che Guevara, el impacto en América Latina y en la Nueva Izquierda occidental de todo este conjunto tuvo una importante relevancia. Por ejemplo, los planteamientos de Debray y el Che fueron analizados y difundidos en diversas publicaciones y, a su vez, los ensayos de la intelectualidad europea circularon en Cuba y en otras revistas de América Latina (Gracia 47).

Nunca como en enero de 1968 fue tan abrumador el apoyo de los intelectuales a la causa de la Revolución cubana y del Tercer Mundo. La reciente muerte del Che-que vista en perspectiva resultó ser un golpe demoledor a la idea de la toma del poder por la vía de la violencia- fue un estímulo que contagió el deseo de combatir y desató el ímpetu revolucionario, como no tardaría en verse, incluso en varias de las grandes capitales europeas. (Fornet 40)

Fue en este escenario de finales de los sesenta cuando surgió la revista Tricontinental. Su desarrollo y calado tuvo mucho que ver con la evolución de la izquierda global, por un lado, y del gobierno cubano -sobre todo respecto a su política exterior-, por otro. La teoría foquista de Guevara -hasta su muerte en 1967- se convirtió en una herramienta fundamental, orientando la ideología e inspirando a los insurgentes que se alineaban con Cuba. Del mismo modo, "para la dolorosa comprensión de muchas guerrillas", aplastar los focos guerrilleros se convirtió en la obsesión estadounidense hacia América Latina (Childs 598). Y es que el triunfo cubano dio inicio al proceso en el que se concebía la posibilidad de trasladar la experiencia cubana a otros países del continente, pero también produjo la reacción de los mecanismos para su contención. Estados Unidos, en connivencia con los gobiernos dictatoriales de la región, desarrollaron una política represiva que afectó tanto a los movimientos revolucionarios, como 
a otras fuerzas no violentas de la izquierda y a partidos y organizaciones que disentían con aquellos regímenes (Gracia y Rey 31). El resultado fue la Doctrina de la Seguridad Nacional, que militarizó ampliamente gran parte de los países latinoamericanos contra cualquier amenaza «comunista» (Kapcia 119). Para Domínguez (42), la importancia de la teoría del foco en la política exterior de Cuba en la década de 1960 se constata con el hecho de que se convirtió en el principio rector de las organizaciones internacionales cubanas OSPAAAL y OLAS, que buscaban combatir el aislamiento de la isla y la supervivencia del gobierno revolucionario, así como promover sus intereses y realzar su influencia. El Che no estuvo presente en ninguna de las reuniones de estos organismos, pero sirvió de inspiración en su ausencia. No obstante, algunos autores señalan que la identificación «tan íntima» de estos eventos con Guevara hizo «difícil» su supervivencia tras su muerte (Gott 39). De hecho, en los escasos trabajos académicos que versan sobre estas organizaciones, se afirma que, a pesar de constituir un intento por encontrar una alternativa revolucionaria a la Unión Soviética y a China, fueron rápidamente derrotadas en 1968 (Grenat 291). Y es que ese deseo expreso cubano de ser vanguardia revolucionaria le granjeó numerosas disputas, sobre todo con Moscú, que en ese año redujo el ritmo de suministro de productos petroleros a Cuba, suspendió el envío de armas y congeló toda asistencia técnica (Domínguez 246). Con la derrota de las guerrillas foquistas y la desaparición física del Che, la postura cubana fue convergiendo con la ortodoxia, por lo que desde La Habana se moderaron lenguaje y posiciones. Según Fornet (31), la crítica pública a los soviéticos cesó en 1969, cuando Fidel Castro reconoció la solidaridad y la ayuda de la potencia, a pesar de la disparidad de criterios que habían mantenido en algunas cuestiones; y ya en 1970 el primer ministro cubano manifestó que era posible llegar al socialismo a través de las urnas, un mes antes de la victoria de Salvador Allende en Chile.

El método foquista, por tanto, había demostrado en la práctica carencias de importante calado, aunque siguió siendo referencia para la reformulación y superación de la acción revolucionaria por parte de las guerrillas urbanas del Cono Sur y las organizaciones político-militares centroamericanas en las décadas siguientes. La propia revista Tricontinental dio testimonio de estos nuevos planteamientos, con la publicación, por ejemplo, de textos sobre los Tupamaros (Núñez 43), el "Minimanual del guerrillero urbano" de Carlos Marighella (15), el programa del Frente Sandinista de Liberación Nacional (FSLN 61) o las luchas en El Salvador (Mármol 4), entre otros. ¿Qué pasó entonces en cuanto al Che? Si desde La Habana se tendió hacia la ortodoxia y a un relajamiento del discurso, ¿cuál fue la postura de la OSPAAAL a través del órgano de su Secretariado Ejecutivo radicado en Cuba? 


\section{CARACTERIZACIÓN DE LA FUENTE Y EL SUJETO: LA REVISTA TRICONTINENTAL Y EL CHE}

La revista Tricontinental constituyó el órgano de la OSPAAAL, organismo en funcionamiento durante más de medio siglo (Camacho y Palieraki 410), cuya misión consistía en asistir la solidaridad entre los pueblos de África, Asia y América Latina, enarbolando la defensa de la independencia de las naciones, la soberanía y la autodeterminación, el respeto por la identidad y la diversidad étnico-cultural y el desarrollo social y la justicia. Sus objetivos estaban encaminados a "lograr una mayor comprensión" de los problemas que acuciaban al Tercer Mundo y cómo superarlos mediante "acciones eficaces". Al mismo tiempo, fue el instrumento de denuncia de "la política criminal de intervención, saqueo y agresión" del imperialismo norteamericano (Editorial 1). El entonces secretario adjunto de la OSPAAAL, Domingo Amuchástegui, junto a varios colaboradores, comenzaron a establecer las condiciones para la creación de una revista que plasmara todos estos principios rectores. Tricontinental comenzó a circular en el verano de 1967, bajo la dirección de José Pérez Novoa, jefe del departamento Socio Cultural de la organización (Estrada 2), como "órgano de agitación, difusión e intercambio de experiencias e ideas entre los hombres que luchan, sienten y piensan en la libertad plena de la humanidad" (Suárez 5).

De carácter bimensual, la publicación estaba concebida para dar cabida a artículos teóricos, de información y orientación de opiniones, firmados fundamentalmente por los principales líderes políticos de los tres continentes, no siendo "la hechura de un equipo de periodistas" (Cervantes 735). Con tiradas iniciales de unos 50.000 ejemplares, la revista se distribuía mediante subscripción entre los movimientos revolucionarios de los tres continentes, así como a personalidades y partidos de izquierda de todo el mundo, con un alto índice de recepción entre los círculos intelectuales y académicos europeos (Calvo). Esta difusión internacional estaba avalada por la existencia de ediciones en español, inglés, francés e italiano, y en 1982 con algunos ejemplares en árabe. Con el número 130 a principios del año 1990 se puso fin a la primera etapa de la revista, una desaparición impuesta por la coyuntura económica de Cuba tras la desintegración de la Unión Soviética. En 1995 se restauró su impresión, pasando al formato digital en los últimos tiempos. ${ }^{4}$

$4 \quad$ Información extraída de la entrevista a Santiago Feliú Miranda, último responsable de la revista Tricontinental, realizada el 22 de mayo de 2019 en la sede de la OSPAAAL (La Habana, Cuba), unas semanas antes de su cierre. 
El estudio de Tricontinental ha generado interés en años recientes, con trabajos que exploran principalmente su primera época y la descripción cualitativa y cuantitativa de los contenidos tratados (Moro; Morales Campos, "45 años"; Abreu Generoso; Calvo). No obstante, son pinceladas de una temática a desarrollar, que se enmarca en el exiguo estado de la cuestión acerca de la OSPAAAL y la OLAS, sobre todo respecto de América Latina y su influencia en la izquierda de la región (Grenat 305). No ocurre lo mismo con Ernesto Guevara, una producción que comenzó él mismo en 1960, con la publicación de su Guerra de Guerrillas, y que ha discurrido incesante hasta hoy día, con biografías, ensayos, análisis e investigaciones sobre su vida y obra, y la trascendencia de ambas, desde múltiples puntos de vista, tanto a favor como en contra. ${ }^{5} \mathrm{El}$ presente trabajo es un grano de arena más en la extensa playa de opúsculos sobre el Che, tomando su figura como paradigma ideológico de la Nueva Izquierda global y como concitadora de voluntades alrededor del proyecto revolucionario orquestado en Cuba. La originalidad de la propuesta reside en barajar como hipótesis la centralidad cubana en la difusión del legado del Che, con la revista Tricontinental como unos de los instrumentos utilizados para tal objetivo.

La metodología utilizada para el análisis que sigue se ha cimentado en la base de datos de la revista Tricontinental, tomando los números comprendidos entre abril de 1967 y julio-agosto de 1990 -130 ediciones y un suplemento especial ${ }^{6}$-, que conforman la primera etapa de la publicación y confluye con la oleada de la Nueva Izquierda. Esta herramienta permite una concepción global del órgano de la OSPAAAL y el establecimiento de conclusiones generales que superen los tradicionales estudios cronológicos y de análisis de contenido. Asimismo, sirve para dar respuesta a los planteamientos sobre los procesos de difusión y su impacto en la propagación (Givan et. al. 1), profundizando en qué se difunde y cómo ocurre esta difusión en el nivel emisor y mediador del objeto de estudio.

\section{CREAR, DOS, TRES, MUCHOS CHE}

En un informe de la CIA de mayo de 1968 se reportaba que, desde la muerte de Guevara, en Cuba "se habían inventado elaboradas mitologías" y "se había

5 El ejercicio historiográfico acerca de Ernesto Che Guevara que abarque de forma total sus obras y las que tratan algún aspecto sobre él estaría por hacer.

6 Base de datos de elaboración propia con los números de la revista Tricontinental recabados en el archivo de la Organización de Solidaridad con los Pueblos de África, Asia y América Latina (OSPAAAL) -La Habana, Cuba- y el International Institute of Social History (IISH) -Ámsterdam, Países Bajos-. 
fomentado el folclore" para ilustrar las "hazañas guerrilleras", teniendo como punto álgido declarar 1968 como "Año del Guerrillero Heroico" ("Political" 3). La agencia estadounidense ilustraba de este modo el esfuerzo del gobierno revolucionario por mantener vivo el espíritu del Che, en quien se encarnaban las pretensiones de la política exterior cubana en el corto plazo. La OSPAAAL era uno de los organismos encargados de ello:

Desde aquel aciago octubre de 1967, la OSPAAAL asumió como sagrado el deber de sembrar y multiplicar su pensamiento [del Che], de compartir la agudeza de sus análisis, de contribuir a la universalización de su ejemplo, de ubicar como eje central de nuestra proyección política la forja y defensa de la unidad antiimperialista del Tercer Mundo, premisa de su fortaleza y avance. No se trata de tareas específicas, sino de un empeño permanente que hemos logrado desarrollar [...] a través los años, concretarlo en una diversidad de iniciativas que favorecen el estudio y el debate del ideario del Che, motivar que por admiración y convicción su iconografía acompañe cada rincón del planeta en el que se combate una injusticia, mantener su herencia vital $[\ldots]$ recrea la certidumbre de que permanece vivo, que nos acompaña (Cervantes 738).

Figura 1. Evolución temporal de las entradas sobre y por el Che en la revista Tricontinental 1967-1990.

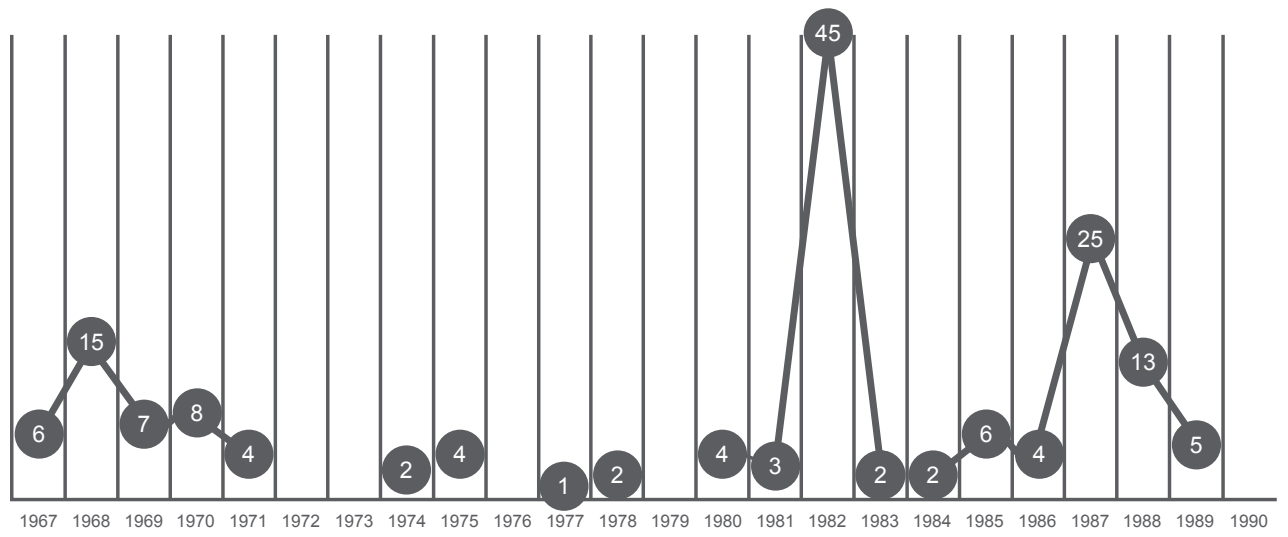

Fuente: elaboración propia en base a revista Tricontinental en el Archivo OSPAAAL (Cuba). 
Los 130 números de la revista contemplados para el presente estudio albergan un total de 1.486 entradas en la base de datos, de las cuales 159 versan sobre el Che. ${ }^{7}$ Esto supone que un $10 \%$ de los contenidos de Tricontinental entre 1967 y 1990 contenían referencias al "guerrillero heroico". Para ponerlo en perspectiva comparada y denotar la atención preferencial a Guevara, sobre Vietnam -otro de los temas "estrella" de la revista, sobre todo en la primera década (Calvo)- existen 66 entradas en la misma etapa, que en términos porcentuales es un $4,45 \%$, casi seis puntos menos. Por tanto, la revisión general de la publicación nos señala que el médico argentino gozaba de un lugar prioritario en la agenda del medio.

Resulta interesante la evolución temporal de la inserción de piezas sobre el Che (fig. 1), donde observamos que de una inicial avidez por difundir su legado -en la línea de lo que comentaban los informes de la CIA tras su muerte, mencionados anteriormente-, se pasó a un letargo en la década de 1970, para tener su máximo esplendor en los ochenta. Fue en estos años cuando se dedicaron dos monográficos a su figura -el no. 83 en 1982 y el no. 113 en 1987-, lo que explica los picos de máxima difusión en esas fechas. Este dibujo se corresponde fielmente a lo explicado por Kapcia (108) acerca del resurgimiento por el interés y el conocimiento de las ideas de Guevara. Según el autor, sus escritos habían sido difíciles de encontrar en la isla desde principios de los setenta, ya que "contradecían claramente" las políticas que estaba siguiendo el gobierno cubano que, como se ha comentado, defendían una interpretación más ortodoxa del comunismo ligado a la Unión Soviética. De este modo, la figura del Che "tendió a permanecer más como una imagen edificante (incluso santa), que como una realidad", hasta que en la década de 1980 se produjo "un resurgimiento de esas ideas, una reimpresión de su trabajo y un reexamen de su validez" (Feliú 5). A la luz de los datos arrojados por la figura 1, la revista Tricontinental fue uno de los instrumentos utilizados desde Cuba para revivir su vida y obra, sobre todo a partir del año 1982.

7 Por entradas nos referimos a cada una de las fichas creadas en la base de datos, en donde se recoge la información de fecha, número, sección, autoría, título, página, zona geopolítica a la que se refiere el artículo y temática. 
Figura 2. Muestra de portadas Tricontinental y carteles OSPAAAL sobre Guevara.
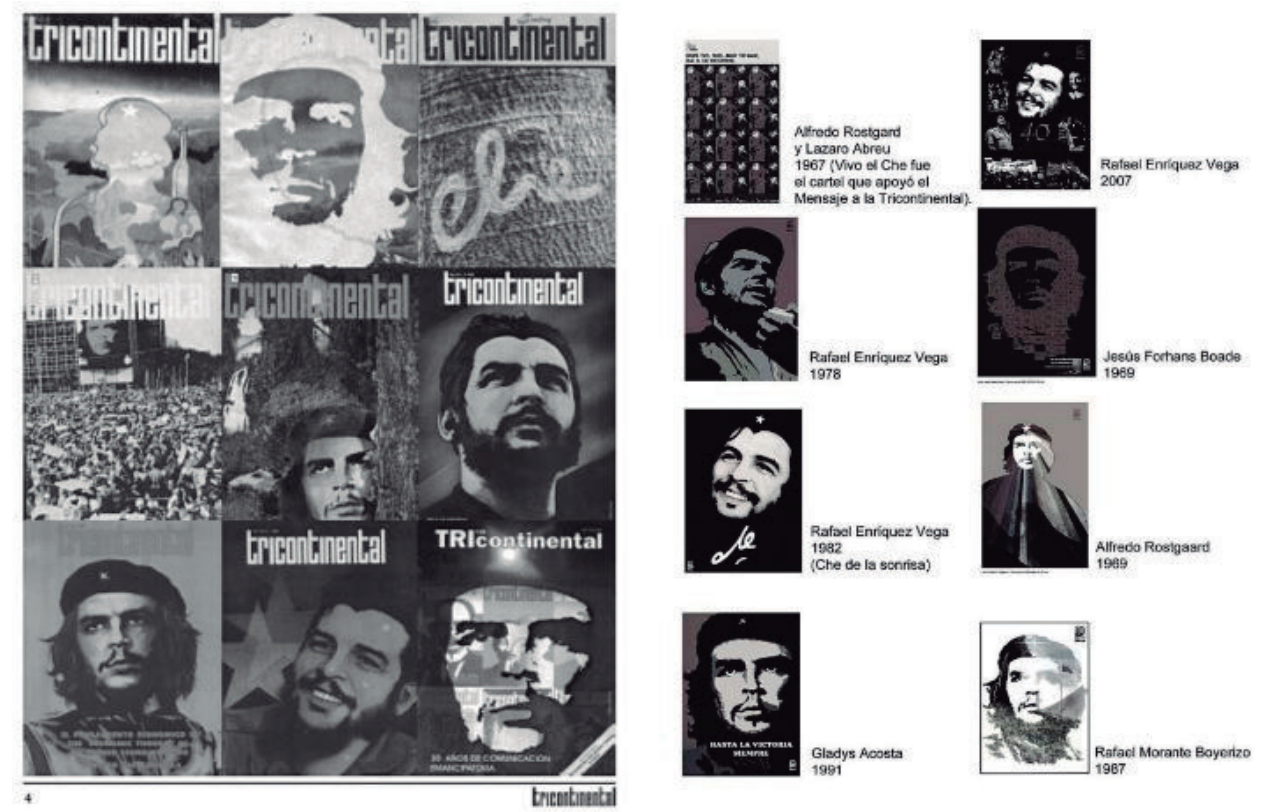

Fuente: Tricontinental, no. 174, 2012, p. 4 y Archivo OSPAAAL.

Figura 3. Evolución temporal de portadas y carteles sobre Che Guevara en la revista Tricontinental 1967-1990.

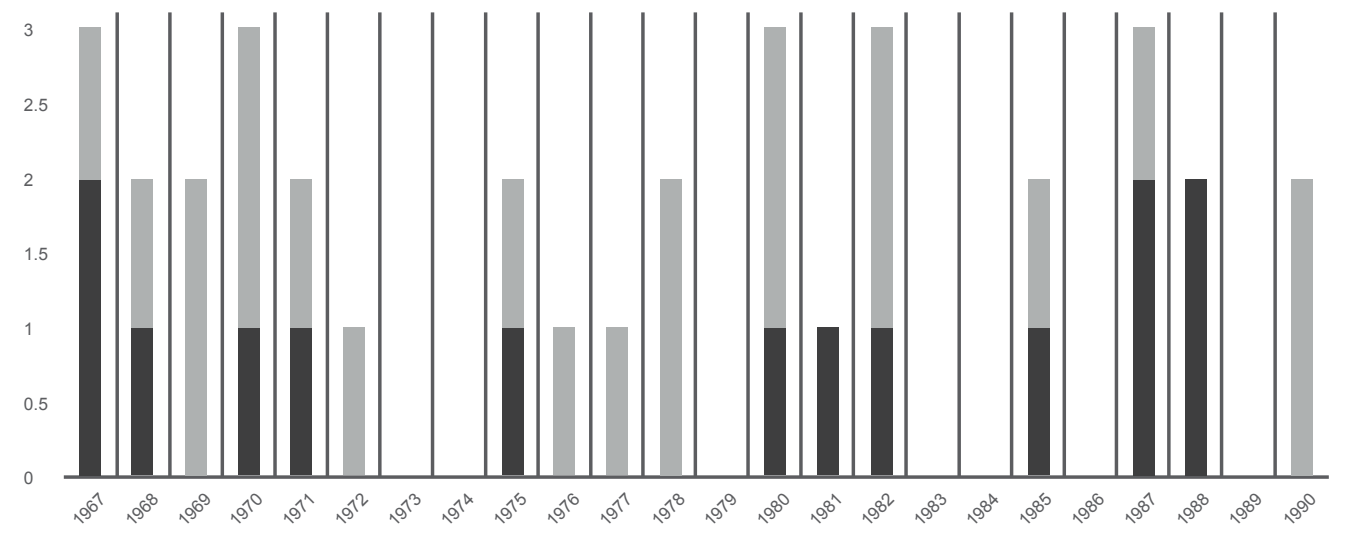

Fuente: elaboración propia en base a revista Tricontinental en el Archivo OSPAAAL (Cuba). 
Si nos centramos en la parte iconográfica, el desarrollo cronológico de las portadas protagonizadas por el Che -un total de 14 entre 1967 y 1990 - tiene un dibujo similar al referido respecto del cómputo global (fig. 3). La aparición de Guevara en la primera plana era sinónimo de que se hacía referencia a su figura en el interior, cosa que no ocurría con otras manifestaciones gráficas. Y es que, aunque no formaban parte de la paginación de la revista, hay que tener en cuenta, en lo referente a la difusión de la imagen de Guevara, los carteles que se incluían en el centro de la publicación, doblados en cuatro partes, que definieron el llamado "estilo Tricontinental". ${ }^{8}$ Sobre la época objeto de estudio, en el archivo de la OSPAAAL se conservaban un total de 21 afiches protagonizados por el guerrillero. El primero salió el 16 de abril de 1967, distribuido dentro de la edición especial de la revista "Crear dos, tres... muchos Vietnam. Mensaje del Che a la Tricontinental", donde se plasmaban tres fotografías de Guevara durante su misión internacionalista en el Congo en 1965 (Morales Campos, "El Che"). La temporalidad que refleja la figura 3 respecto a los carteles denota una mayor constancia en comparación con los contenidos de la publicación, notoria en las dos primeras décadas y con más silencios en la última. La adopción de un nuevo formato para la revista en los ochenta, ${ }^{9}$ así como la reducción de la tirada ante el aumento del coste de los insumos gráficos en el mercado internacional, ${ }^{10}$ son algunos factores que explican esta tendencia irregular en la difusión de afiches sobre Guevara por parte de la OSPAAAL en este último periodo. Asimismo, al contrario que pasaba con las portadas, la inclusión de un cartel sobre el Che no significaba que la revista incluyera algún texto de su autoría o sobre él.

Respecto a los contenidos de las piezas, la figura 4 refleja que esa parte iconográfica acerca del Che representa un $23 \%$ del total -entre portadas e imágenes en las páginas interiores-, sobresaliendo los artículos que versaban sobre la figura de Guevara $-40 \%-$, seguidos por aquellos que eran de su propia autoría $-23 \%$ - y por los que versaban sobre otros asuntos, pero era citada su figura $-14 \%$ - . Esta cuantificación señala que la revista Tricontinental priorizó textos acerca del guerrillero de diversa índole temática y autoría, como se verá más adelante. Se trata de una tendencia que daba continuidad a una producción

8 Sobre los carteles de la OSPAAAL en general, véase Rodríguez Bermúdez, y Frick y Estrada.

9 De 1967 a 1983, Tricontinental se difundió en formato tipo libro, cuyas medidas eran 23 x 15 centímetros y 120 páginas. Desde 1983 hasta 1990 el formato pasó a ser de 21 x 28 centímetros y unas 80 páginas.

10 La tirada inicial de 50 mil ejemplares por número (25 mil en español, 15 mil en inglés y 10 mil en francés), en la década de 1980 se redujo a 25 mil (12 mil en español, 8 mil en inglés y 5 mil en francés) y las reproducciones de carteles se limitaron a 5 mil en papel cromado y 3 mil en papel bond (Morales Campos, "45 años"). 
iniciada en 1959, ya que, como señala Anderson (364), en ese año se iniciaron "homenajes líricos al Che", cuando Nicolás Guillén, "el mayor poeta vivo de Cuba" que vivía en el exilio en Buenos Aires, escribió un poema en su honor "a petición del director de un semanario de la capital argentina": 11

El Che ya era una figura conocida por los lectores en el exterior, pero su consagración literaria a manos de Guillén -un poeta a la altura de Federico García Lorca, Pablo Neruda y Rafael Alberti- lo introdujo en el panteón de los héroes venerados de la historia latinoamericana. Tenía apenas treinta años y ya lo comparaban con el Libertador José de San Martín. Estos elogios hiperbólicos repercutían en la opinión pública cubana, ávida de héroes (Anderson 364).

En cuanto a la temática, la figura 5 revela que la lucha armada y el antimperialismo fueron las cuestiones más tratadas en los textos escritos sobre y por el Che en las páginas de Tricontinental, seguidas por la iconografía (portadas e imágenes), los editoriales y las semblanzas. En una proporción menor, estarían las cartas del guerrillero, los poemas sobre su persona y el internacionalismo, así como canciones y artículos que incidían en contenidos doctrinales, de su faceta como médico y periodista, cultura, economía, etc. ${ }^{12}$

11 Se trataba del semanario Propósitos (véase Pérez Galdós Ortiz). El poema del autor cubano, titulado "Che Comandante", se incluyó también en los números 83 y 113 de Tricontinental (Guillén 144 y 83). La revista publicó asimismo poesías dedicadas a Guevara por parte de los cubanos Mirta Aguirre (12) y Miguel Barnet (29), del argentino Julio Cortázar (54) y del gallego Celso Emilio Ferreiro (136).

12 Varias categorías temáticas pueden estar presentes en una misma pieza, pero en estos casos se ha optado por reflejar la que presenta mayor entidad en cada unidad de análisis. 
Figura 4. Tipología de contenidos sobre y por el Che en Tricontinental 1967-1990.

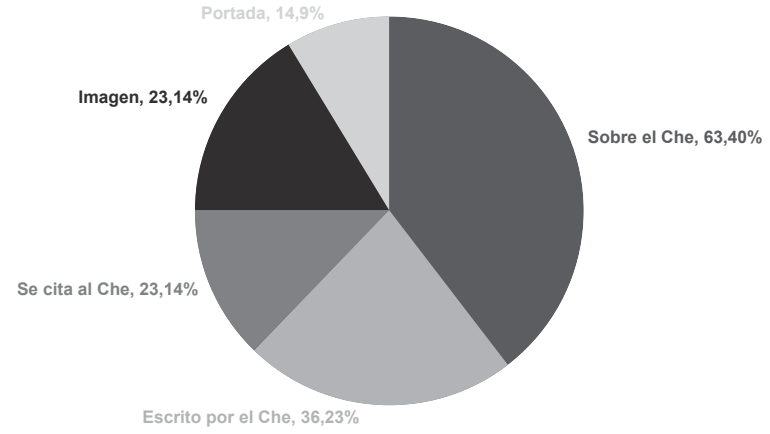

Fuente: elaboración propia en base a revista Tricontinental en el Archivo OSPAAAL (Cuba).

Figura 5. Temática de las piezas sobre y por el Che en Tricontinental 1967-1990.

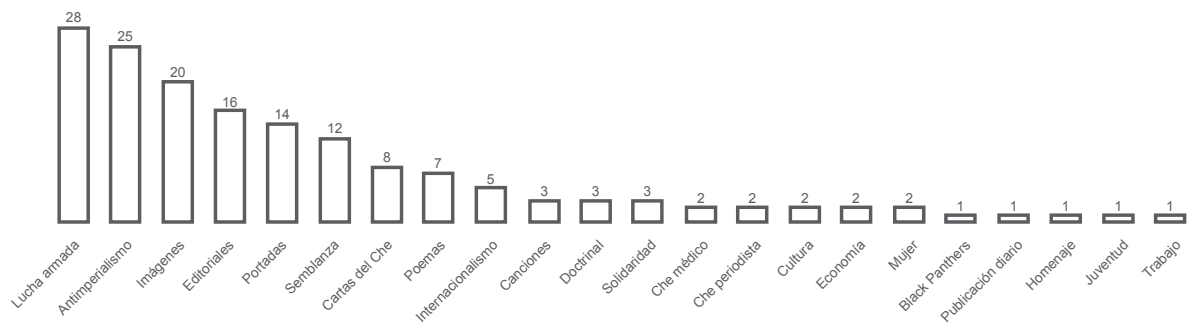

Fuente: elaboración propia en base a revista Tricontinental en el Archivo OSPAAAL (Cuba).

Figura 6. Procedencia autoría de las piezas sobre y por el Che en Tricontinental 1967-1990.



Fuente: elaboración propia en base a revista Tricontinental en el Archivo OSPAAAL (Cuba). 
Resulta interesante reseñar la procedencia de la autoría de todas estas inserciones vinculadas con Ernesto Guevara, que, como indica la figura 6, emanaban fundamentalmente de la propia OSPAAAL y de Cuba, junto a los propios textos del Che, lo que supone un $82 \%$ de los contenidos emitidos en cuanto al guerrillero argentino. Esto es indicativo de esa construcción y promoción consciente de su figura que se enarbolaba desde la isla, coadyuvando a una propaganda de raíces endógenas con visos de internacionalización, dado el perfil de la publicación en la que se enmarcaba. Por tanto, las cifras apuntan a que la difusión del legado de Guevara fue efectiva y con una constancia relativa en los años objeto de estudio dentro de Tricontinental, propalando la visión construida desde Cuba e incidiendo en contenidos acerca de la lucha armada y el antimperialismo, en los que cumple profundizar.

\section{TRICONTINENTAL Y CHE: LUCHA ARMADA Y ANTIMPERIALISMO}

Los textos relacionados con Guevara que trataban la lucha armada y el antimperialismo fueron los que gozaron de mayor espacio y tratamiento dentro de Tricontinental, como refleja la figura 5, suponiendo el $15 \%$ y el $14 \%$, respectivamente. De hecho, la revista comenzó su andadura con una edición especial, publicada en abril de 1967, bajo el título "Crear dos, tres... muchos Vietnam, es la consigna", firmado por el Che, donde incidía en ambas temáticas. El adelanto de este texto fue una decisión del Secretariado Ejecutivo de la OSPAAAL, con el objetivo de "dar a la publicidad este transcendental mensaje a los pueblos del mundo, del heroico y legendario combatiente, sin esperar a la publicación del primer número de nuestra revista" (Prensa Latina, "Envió" 1). ${ }^{13}$ El primer secretario general de la organización, Osmany Cienfuegos, justificaba este suplemento extraordinario dada la "importancia" del contenido del texto:

[...] por la claridad con la que aborda problemas de vital importancia para el movimiento revolucionario, por la denuncia enérgica que contiene de la política adoptada por el imperialismo yanqui de enviar soldados norteamericanos a reprimir los movimientos revolucionarios de liberación en cualquier parte del mundo donde surjan, tal como lo ha hecho no sólo en Viet Nam y Santo Domingo,

13 El primer número de la revista Tricontinental salió en julio-agosto de 1967. 
sino también en Guatemala, Colombia, Venezuela y Bolivia, países donde ya se encuentran numerosos miembros «boinas verdes» de las fuerzas especiales, y por el vigoroso llamado con que exhorta a los pueblos a dar condigna respuesta a esa criminal política (Prensa Latina, "Envió" 1). ${ }^{14}$

El documento -que según Taibo II (675), conformó la base de la propuesta cubana y de toda la izquierda radical al final de la década de 1960- era, a la vez, un análisis de los conflictos en el Tercer Mundo y un llamamiento: "toda nuestra acción es un grito de guerra contra el imperialismo y un clamor por la unidad de los pueblos contra el gran enemigo del género humano: los Estados Unidos de Norteamérica" (Guevara, "Mensaje" 24). En esa época, el guerrillero argentino tenía en jaque a todos los servicios de inteligencia occidentales y a la opinión pública en general, ya que se encontraba en paradero desconocido -de hecho, su artículo propagado desde Cuba lo subtitularon "enviado desde algún lugar del mundo" (Prensa Latina, "Texto" 1). La propia CIA, en agosto de 1967, no tenía "evidencias concluyentes" de si estaba participando en algún movimiento guerrillero o incluso de si estaba vivo (CIA, "The Bolivian" 4). Lo cierto es que Guevara se encontraba en Bolivia desde finales de 1966 y, tras su Mensaje a la Tricontinental, la agencia estadounidense concentró esfuerzos para encontrarlo (Anderson 670). La muerte de Guevara en tierras bolivianas en octubre de 1967 supuso cambios sustanciales en el discurso y en la política exterior cubana, como ya se ha señalado, pero no impidió que las palabras del Che y su influencia en los movimientos revolucionarios e independentistas alrededor del mundo tuvieran cabida en el órgano de la OSPAAAL.

Tras ese primer artículo cuasi profético -"En cualquier lugar que nos sorprenda la muerte, bienvenida sea" (Guevara, "Mensaje" 24)- y redefinido como "su Testamento Político" ("Al lector" 1967, 3), la temática antimperialista y de lucha armada siguió presente en Tricontinental, fundamentalmente en dos momentos: en los primeros años hasta 1971 y en la década de 1980 (fig. 8). En cuanto a los textos del inicio, estos se vinculan, sobre todo, al recuerdo de su persona -con piezas acerca de su vida y accionar- y a ser citado como ejemplo a seguir en escritos de otros movimientos armados.

14 Otros medios cubanos, como Granma o Prensa Latina, entre otros, reprodujeron también el texto íntegro del comandante Guevara en abril de 1967 (Taibo II 675; Prensa Latina, “Texto” 1). 
Figura 7. Portada del no. 2 de Tricontinental (sept.-oct. 1967), con el manuscrito del texto del Che "Crear dos, tres... muchos Vietnam, es la consigna", en homenaje tras su muerte.
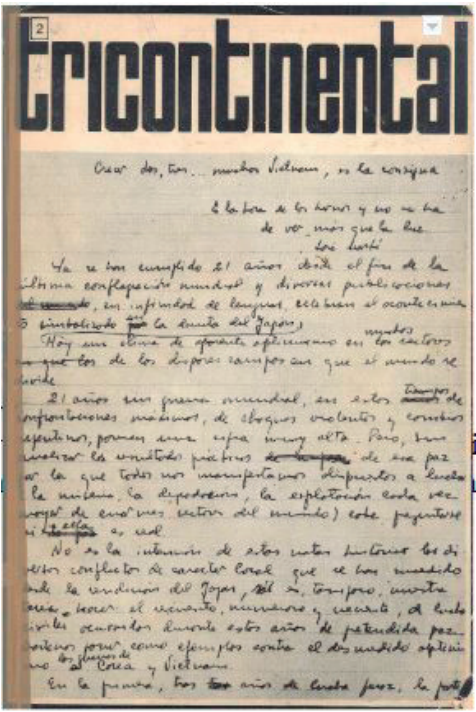

Fuente: Tricontinental, no. 2, 1967 en Archivo OSPAAAL

Figura 8. Evolución temporal de las piezas sobre y por el Che en cuanto a lucha armada y antimperialismo, Tricontinental 1967-1990.

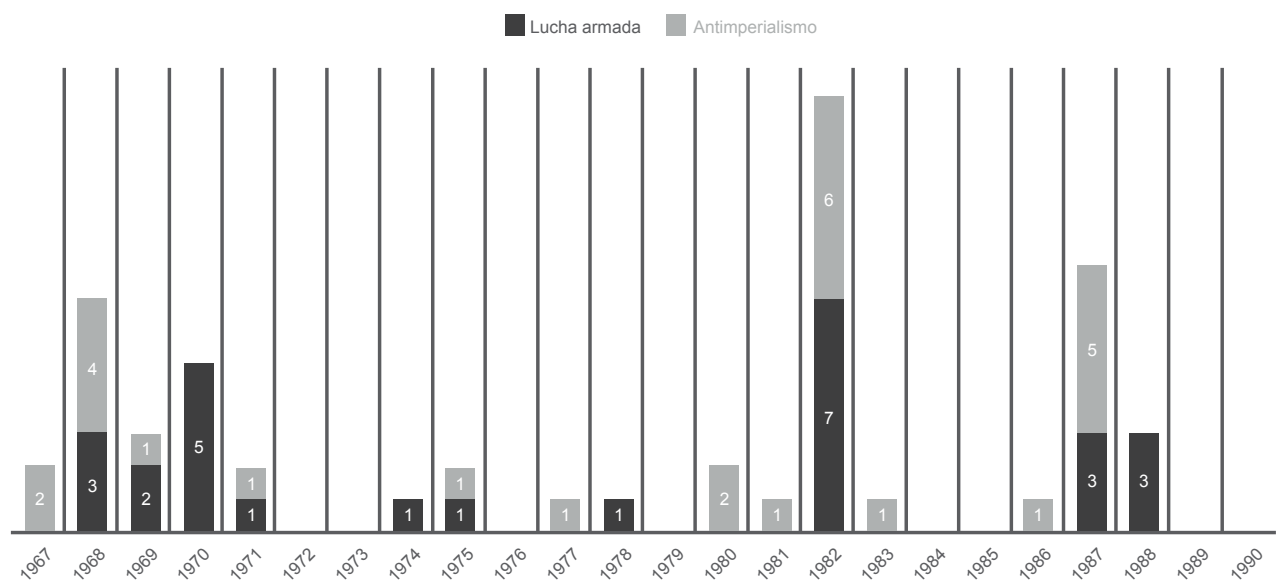

Fuente: elaboración propia en base a revista Tricontinental en el Archivo OSPAAAL (Cuba). 
En el no. 2 de la revista -publicado tras su muerte (fig. 7)- se incluye un texto de la autoría del Che bajo el título "Internacionalismo y antimperialismo", que corresponde a su intervención en el Seminario Económico Afroasiático, realizada en Argel en el año 1965. En la introducción al discurso de Guevara, este es calificado como "su testamento económico, o por lo menos, una faceta del mismo":

No necesitó usar cifras o cuadros estadísticos para exponer la situación del mundo afroasiático y latinoamericano. Fustigó acremente al imperialismo, pero también hizo señalamientos importantes al referirse al intercambio desigual planteado sobre la base de los precios que la ley del valor impone a los países atrasados. El aspecto de la lucha de liberación nacional y las normas que deben regir el verdadero internacionalismo proletario fueron netamente subrayadas. (Guevara, "Internacionalismo" 20)

En estas primeras ediciones, el antimperialismo también estuvo presente en el no. 8 -que conmemoraba el primer aniversario del combate de la quebrada del Yuro, última acción librada por Ernesto Guevara al frente del Ejército de Liberación Nacional de Bolivia (ELN)-, con otro texto del Che bajo el título "El papel que nos corresponde". La revista ofrecía en esta ocasión fragmentos de discursos, intervenciones y escritos de distintas etapas del comandante, a modo de selección de su pensamiento sobre los problemas del mundo tricontinental, centrados en presentar batalla al imperialismo: "Al imperialismo hay que darle en el hocico una vez y otra vez, y otra vez más, y en una sucesión infinita de golpes y contragolpes; es la única forma en que el pueblo puede adquirir su real independencia" (Guevara, "El papel" 27). En este número también se publicaba un artículo de Kim Il Sum, donde el líder norcoreano rendía homenaje al guerrillero argentino con palabras que aludían a la realidad sociopolítica de aquella época, de crítica abierta a Estados Unidos:

[...] los imperialistas yanquis, agitando el olivo en una mano y la flecha en la otra, combinando el chantaje nuclear con la «penetración pacífica», y la represión con la conciliación y el engaño, planean conquistar uno por uno mediante la agresión armada a los países revolucionarios y descomponer a los países ideológicamente débiles por medio de la invasión ideológica y cultural (Sung 13). 
La lucha armada tuvo su espacio, en esta primera etapa, tanto en textos escritos por Guevara como en otros que versaban sobre él o era citado. De su autoría fueron "Instrucciones para los cuadros destinados al trabajo urbano" (93-96) y "Táctica y estrategia de la revolución latinoamericana" (4-13). El primero era una relación de tareas destinadas a los militantes del ELN, con el objetivo de formar una red de apoyo a la guerrilla rural en las ciudades, de naturaleza "fundamentalmente clandestina". Destacaba la necesidad de organizar abastecimientos, transporte, información, finanzas, las propias acciones urbanas y la atención a simpatizantes, sobre todo en las ciudades que consideraba importantes -Cochabamba, Santa Cruz, Sucre, Camiri, en "el rectángulo que engloba nuestra zona de operaciones"-. Asimismo, recalcaba la "firmeza ideológica" que debían tener estos cuadros, "entregando todo su tiempo y también su libertad, o su vida si llega el caso", con la finalidad de "la liberación total de Bolivia".

El segundo de los textos era un análisis de Guevara escrito en 1962 -"no fue publicado en vida del autor y luego de su muerte ha tenido escasa difusión" (Guevara, "Táctica" 11)- acerca de las posibilidades revolucionarias en América Latina. El Che comenzaba recalcando que el "gran y definitivo" objetivo estratégico de las fuerzas revolucionarias era la toma del poder, sin limitarse al marco de una entidad geográfica o social. Además, respondía "rotundamente" no a si era posible tomar el poder por la vía pacífica en el subcontinente con las condiciones que presentaba en aquel entonces: "las armas en manos del pueblo, las vastas comarcas de nuestra América como campo de acción, el campesinado luchando por su tierra, la emboscada, la muerte inmisericorde al opresor $\mathrm{y}$, al darla, recibirla también y recibirla con honor revolucionario" (Guevara, "Táctica" 11).

A propósito de la lucha armada, el comandante Ernesto Guevara era citado en 1968 en un comunicado conjunto de las Fuerzas Armadas Rebeldes y el Movimiento Revolucionario 13 de Noviembre de Guatemala. En él, señalaban al Che como inspiración y ejemplo a seguir, considerando las armas como "único camino para lograr la libertad y la independencia" y la violencia revolucionaria como mecanismo para "responder y aplastar la violencia reaccionaria" (Montes y Sosa 77-78). En el no. 16 de 1970, Tricontinental publicaba el "Minimanual del guerrillero urbano" de Carlos Marighella (15), que definían como "uno de los libros de cabecera de todo hombre que, consecuente con la inevitable batalla contra la burguesía y el imperialismo, tome la vía de las armas". Entre las instrucciones establecidas por el guerrillero brasileño, señalaba que la militancia armada implicaba "un mínimo de conocimientos políticos" y, por ello, instaba a leer, entre otras obras, Guerra de Guerrillas de Che Guevara (19). Ese mismo 
año, en el no. 17, en un texto firmado por los Tupamaros con la crónica de sus acciones, se citaba también esta obra del Che como guía a seguir y se afirmaba que el asalto a la ciudad de Pando el 8 de octubre de 1968 había sido "en honor" al guerrillero argentino ("Uruguay" 46-47). Ya con anterioridad, Carlos Núñez (56) señalaba en el no. 10 de la revista las enseñanzas de Guevara entre los conceptos teóricos que respaldaban las acciones del movimiento de liberación uruguayo: "no hay que esperar a que estén dadas todas las condiciones objetivas y subjetivas para llevar adelante la revolución: la lucha armada (el foco en el planteo del Che) puede crearlas". En el mismo número, se publicaba una entrevista de Tricontinental a George Murray y Joudon Major Ford, integrantes de los Black Panthers, en la que, entre otros asuntos, lamentaban la pérdida del Che y esperaban que América Latina "se convirtiera en un Vietnam" siguiendo su ejemplo ("Black" 109-110).

Sobre Guevara y la lucha armada, las primeras ediciones de la revista contaron con artículos firmados por Fidel Castro y sus compañeros de guerrilla en Cuba y Bolivia. El líder cubano signaba en 1968, en el primer aniversario de la muerte del comandante, el texto titulado "El Che: aliento universal de lucha. Una introducción necesaria", que conformaba el prólogo al diario del guerrillero argentino en Bolivia, próximo a publicarse en aquel año. ${ }^{15}$ Castro afirmaba en esas líneas que no luchar "será el único camino de no obtener jamás la libertad" (102), una lucha en la que la divulgación de la obra simbolizaba, por un lado, dar publicidad a un ejemplo que "los imperialistas yanquis temen" y, por el otro, perpetuar su legado ante "seudorrevolucionarios, oportunistas y charlatanes de toda laya" que veían el desenlace de su lucha en el país andino como el fracaso de sus ideas (101).

En 1970, Tricontinental reproducía el relato que Joel Iglesias hiciera para Verde Olivo -órgano oficial del Ministerios de las Fuerzas Armadas Revolucionarias de Cuba- en ocasión del segundo aniversario de la muerte de Guevara (35). El texto versaba sobre su experiencia al lado del Che en la guerrilla cubana, humanizando la lucha armada y resaltando aspectos personales del comandante. En esta misma línea estaba el relato de tres cubanos que acompañaron al Che en Bolivia, testimonios que se habían publicado previamente

15 En el artículo (111) se señalaba que el Diario iba a ser publicado "de forma aproximadamente simultánea" en: Francia por Editorial Fraçois Maspero; Italia, Editorial Feltrinelli; RFA, Trikont Verlag; EEUU, Revista Ramparts; en español, Ediciones Ruedo Ibérico; Chile, Revista Punto Final, y en otros países. Esta difusión internacional y en diferentes idiomas de la obra es también indicativa de la preeminencia propagandística revolucionaria alentada desde Cuba, en general, y acerca de la figura del Che, en particular. 
en el periódico Granma -órgano del Partido Comunista de Cuba-y que la revista rescató en su no. 19-20. Harry Villegas Tamayo (Pombo), Leonardo Tamayo Núñez (Urbano) y Daniel Alarcón Ramírez (Benigno) ofrecieron así su versión sobre el combate de la quebrada de Yuro, donde el ejército boliviano capturó al Che, resaltando sus cualidades positivas a pesar de la adversidad:

Uno de los aspectos al que hay que prestar más atención para comprender cómo ocurrieron las cosas, está dado por las concepciones humanas del Che. Porque es por eso, por su compañerismo, por sus sentimientos para con los que venían enfermos, y por su responsabilidad como jefe, por lo que él decidió quedarse al frente de la gente que tenía capacidad de combatir y, desplegando la reducida fuerza con que contaba, garantizar que los enfermos pudieran salir del cerco. Y cuando él trató salir del cerco ya no pudo hacerlo porque el ejército había completado su avance y él queda entre varias tropas que lo bloquean por todas las salidas. (Pombo 123)

Como ya se ha comentado, la década de 1970 en Tricontinental fue la más exigua en cuanto a contenidos relativos a Guevara, con poco más de una docena de inserciones a lo largo de los 37 números publicados en esta época, de los cuales tres versaban sobre antimperialismo y cuatro sobre lucha armada. Empezando por esta última temática, el tratamiento era similar a lo referido al final de la etapa anterior, con artículos que hacían alusión a las experiencias guerrilleras del Che en Cuba y Bolivia. En el no. 26 del año 1971 se incluía una documentación de Ernesto González Bermejo titulada "El vado de la traición" (63), un relato acerca del grupo guerrillero asesinado en un remanso del río Grande de Bolivia en agosto de 1967. A este respecto, en la nota introductoria de la revista se insistía en que esta experiencia guerrillera "no fracasó, que fue destruida, pero no derrotada", manifestando que existía "respeto a los principios y gesta del guerrillero ejemplar [Che]" por parte de estudiantes, obreros y campesinos "decididos a alcanzar la definitiva liberación del hombre" ("Al lector" 3). Posteriormente, en 1974, se publicaba el texto de Susana Seleme "Bolivia o el coraje de un pueblo", historiando "los casi cinco siglos de explotación e ignominia" de la nación (19). La autora señalaba que la guerrilla del Che en Bolivia "conmovió las bases de la sociedad, agudizando las contradicciones" y que su muerte "condicionó la radicalización del proletariado, de los sectores revolucionarios, del estudiantado universitario y parte de la clase media" en el país andino (35). 
Sobre la guerrilla cubana, las piezas que hacían alusión al Che se incluyeron en la sección "Libros de Hoy". ${ }^{16}$ En 1975 se difundieron algunos fragmentos del volumen Con la adarga al brazo, del periodista Mariano Rodríguez Herrera (123). Dicha obra había sido publicada tres años antes por el Instituto Cubano del Libro, pero se estaba preparando una nueva edición ampliada, motivo por el cual Tricontinental presentó a sus lectores un adelanto. Estas líneas versaban sobre la experiencia de algunos campesinos que compartieron con el Che su andar guerrillero en Sierra Maestra, de nuevo recalcando la humanidad de Guevara, su tesón y la responsabilidad para con la causa y los suyos: "[...] el cuidado con el hombre, con el ser humano, para formarlo, para ayudarlo, era constante en él” (126). En 1978 fue el turno de 7RR. La historia de Radio Rebelde, firmado por Ricardo Martínez Victores, integrante del Movimiento 26 de Julio durante la etapa insurreccional en Cuba. Se incluyeron varias páginas del volumen, donde se recogen relatos de diferentes integrantes de la guerrilla cubana que participaron en el montaje y funcionamiento de la emisora radial, cuya fundación le atribuyen al comandante Ernesto Guevara (80). De este modo, a pesar de que la difusión de la figura del Che en los años setenta fue residual en las páginas de la revista, observamos que, de un modo u otro, su presencia era constante en el plano divulgativo, como lo señalan estas dos iniciativas editoriales. Por tanto, aunque el discurso oficial se hubiera atemperado, desde Cuba se propendía a la difusión de las gestas pasadas como recuerdo de la victoria, justificación de los medios empleados y aliento para los simpatizantes.

El antimperialismo en relación con Guevara fue tratado en esta década en artículos generales, en los que el guerrillero era citado en alguna ocasión, como en el titulado "Unión sin confines", de Fidel Castro, una reproducción de su discurso de clausura en los actos celebrados por el décimo aniversario de la "Victoria de Girón". El dirigente cubano hablaba del "miedo de los imperialistas" a "la ola revolucionaria" que sacudía América Latina, y que, pese a la muerte del Che, "quedaron sus sentimientos, quedaron sus ideas, quedó su ejemplo" (123). También se hizo referencia al guerrillero en la "Declaración de la Conferencia de los Partidos Comunistas de América Latina y del Caribe", producto de la reunión que se había efectuado en La Habana en junio de 1975. El documento era un análisis de la realidad latinoamericana de aquel entonces, además de un programa de luchas "para los pueblos que todavía sufren la explotación imperialista", cuyo

16 En esta sección -más o menos constante en Tricontinental entre 1967 y 1990- se presentaban capítulos o extractos de obras relacionadas con los objetivos de la OSPAAAL (véase Calvo). 
símbolo era el Che (107). La última referencia a Guevara en esta década en cuanto al antimperialismo vino de la mano de Rodney Arismendi, secretario general del PC uruguayo, que en 1977 lo incluía en el listado de "mártires de la independencia, la democracia y el progreso social" en su análisis acerca de la ola contrarrevolucionaria "desatada por el imperialismo, apoyado por las fuerzas reaccionarias locales" (95).

La década de 1980 fue la más prolija en la revista en cuanto a contenidos referentes al Che, tal y como señalan las cifras, y en los que casi la mitad eran de su propia autoría, confirmando entonces ese resurgir de su figura y sus textos. En cuanto a la lucha armada, Tricontinental publicó en esta etapa dos artículos que habían aparecido en los sesenta en la revista Cuba Socialista: ${ }^{17}$ "Guerra de guerrillas: un método" y "¿Qué es un cuadro?”. El primero, que databa de septiembre de 1963, Childs lo considera "el prefacio a la segunda edición de Guerra de Guerrillas" (616), cuando Guevara repitió y confirmó las tres lecciones del trabajo anterior -que había visto la luz en 1960 en base a la experiencia guerrillera cubana-: ${ }^{18}$

Primero: las fuerzas populares pueden ganar una guerra contra el ejército. Segundo: no siempre hay que esperar a que se den todas las condiciones para la revolución; el foco insurreccional puede crearlas. Tercero: en la América subdesarrollada, el terreno de la lucha armada debe ser fundamentalmente el campo. (Guevara, "Guerra" 43)

Sin embargo, para Childs, Guevara había abandonado en ese texto -y en aquel momento- el "corolario democrático" presente en el anterior (Guevara, "Guerra" 46) ya que, una vez que la política cubana se había vuelto marxista, ya no podía considerar la democracia como "la medida preventiva efectiva para contrarrestar la guerra de guerrillas":

17 Revista teórica y política fundada en 1961, tras declarar el carácter socialista de la Revolución Cubana. Su nacimiento se vinculó "al proceso de organización y educación política de los cuadros revolucionarios, así como para confirmar los objetivos de la Revolución" (Portal 140). De carácter mensual, se editó hasta 1967, publicándose un total de 66 números. El consejo de dirección estuvo formado por Fidel Castro, Osvaldo Dorticós, Blas Roca, Carlos Rafael Rodríguez y Fabio Grobart. Guerra de Guerrillas apareció en abril de 1960, publicado por el Departamento de Instrucción Militar del Instituto Nacional de Reforma Agraria (INRA). Anderson indica que los medios cubanos publicaron largos pasajes del libro y que poco después, tanto cubanos como especialistas en contrainsurgencia de Estados Unidos y América Latina, estudiaron el manual con gran interés (447). 
[...] estaría alegando indirectamente la imposibilidad de condiciones revolucionarias en los sistemas políticos democráticos y, además, descartando el papel de la explotación capitalista objetiva y el compromiso subjetivo con la acción revolucionaria que son primordiales en todos los teóricos revolucionarios marxistas. (Childs 616)

El segundo texto estaba conformado por extractos del artículo "El cuadro, columna vertebral de la revolución", que se había publicado en 1962 y que Tricontinental reprodujo tanto en el monográfico dedicado al Che de 1982, como en el de 1987. El contenido versaba sobre las características que debían albergar los dirigentes revolucionarios tras la lucha y la consecuente toma del poder: desarrollo político, disciplina ideológica y administrativa, valor físico y moral (Guevara, "Qué" 62; "El cuadro" 31), en la línea de su concepción del "hombre nuevo" que desarrolló posteriormente (Guevara, "El Socialismo" 15). No fue el único caso de repetición de textos firmados por el guerrillero. Respecto a la lucha armada, también se incluyó dos veces "El Patojo", tomado de su libro Pasajes de la guerra revolucionaria. En él hacía una semblanza del combatiente guatemalteco Julio Roberto Cáceres Valle, amigo personal del Che que murió "en su tierra con las armas en la mano para repetir en alguna forma nuestra lucha guerrillera" (Guevara, "El Patojo" 92, 18). Las glosas a los "héroes caídos" eran una constante en las publicaciones militantes de la época, que construyeron las figuras de los "mártires" por la causa, siendo el propio Guevara uno de los máximos exponentes. Esta concepción se ha relacionado, en cierta forma, con el concepto de la "bella muerte" en el campo de batalla, con la que el soldado alcanza el valor y la gloria inmortal (Casamitjana 16), convirtiéndolo en un ejemplo a seguir "en la construcción de la nueva sociedad" (Guevara, "El Patojo" 93, 19). 
Figura 9. Reproducción de la última página del Diario del Che en Bolivia. Tricontinental, no. 83, 1982, p. 129

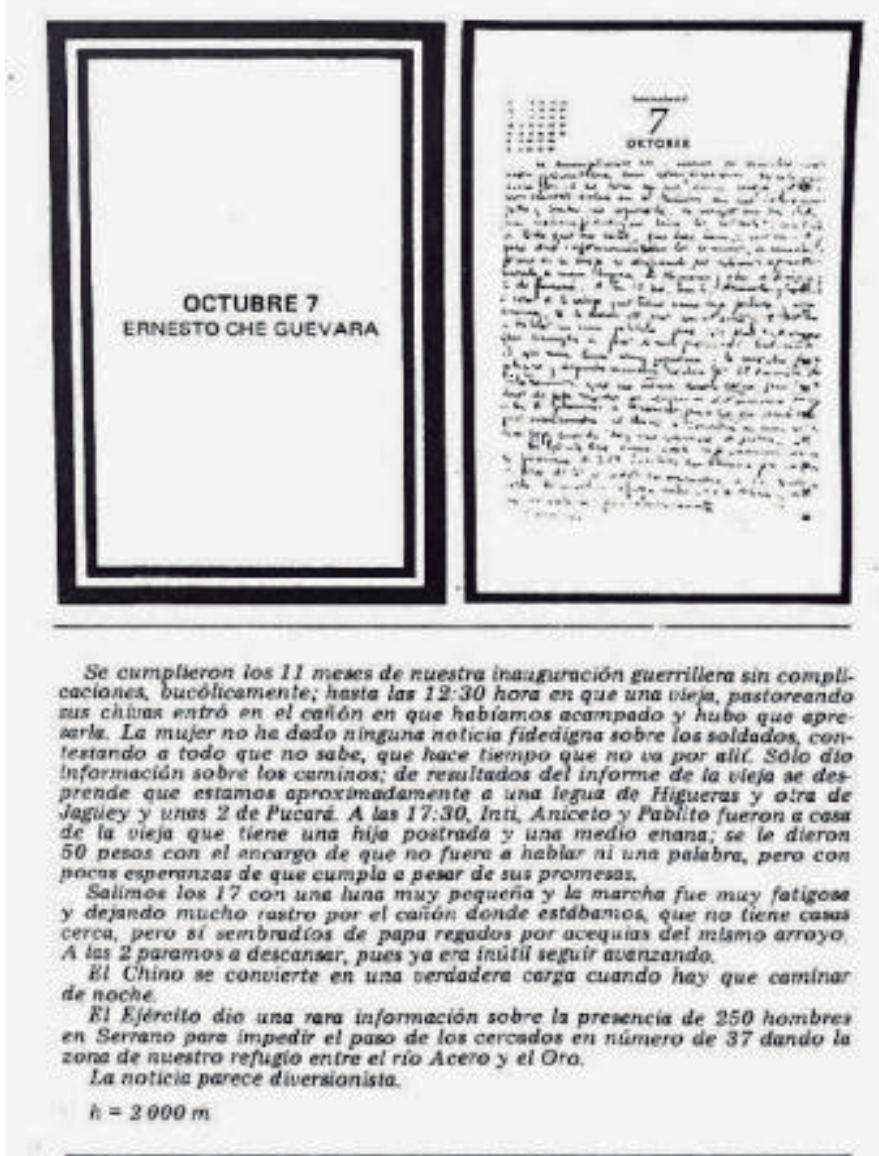

129

Fuente: Tricontinental, no. 83, 1982, p. 129 en Archivo OSPAAAL

La revista, relativo a la vía armada escrito por Guevara, reprodujo en 1982 la última página de su diario en Bolivia (fig. 9) y en 1987 el artículo “¿Qué es un guerrillero?”, previamente difundido en el periódico Revolución el 19 de febrero de 1959, tres días después de que Fidel Castro fuera nombrado primer ministro (Anderson 380). El Che abogaba en el texto por el derecho del Ejército Rebelde a decidir el futuro político de Cuba -sobre todo respecto de la Reforma Agraria-, además de exaltar la figura del guerrillero: "El guerrillero 
es un reformador social [...] empuña las armas como protesta airada del pueblo contra sus opresores, y lucha por cambiar el régimen social que mantiene a todos sus hermanos desarmados en el oprobio y la miseria" (Guevara, "Qué es" 19).

Sobre el Che y la lucha armada en los ochenta, Tricontinental volvió a incluir en 1982 el prólogo firmado por Fidel Castro a su diario en Bolivia en dos artículos: "Una introducción necesaria" (126) y "Che y su ejemplo" (138), que había sido reproducido en extenso en las páginas de la revista en el año 1968, como ya hemos visto. Respecto a la guerrilla boliviana, en ambos monográficos de 1982 y 1987 se publicó el texto "El Yuro", parte del libro Mi campaña con el Che, escrito por Inti Peredo (131 y 48), combatiente del ELN. Las líneas relatan cómo se enteraron de la captura y muerte del Che, tras la dispersión de la guerrilla ante el envite del ejército, un golpe que le sugirió plasmar recuerdos que aluden a la glorificación del mártir y a la muerte como símbolo de una lucha incesante:

Por eso la tarde del 10 de octubre Ñato, Pombo, Darío, Benigno, Urbano y yo dijimos en la selva boliviana: Tus ideas no han muerto. Nosotros, los que combatimos a tu lado, juramos continuar la lucha hasta la muerte o la victoria final. Tus banderas, que son las nuestras, no serán arriadas jamás. ¡Victoria o muerte! (Peredo 51)

La revista también rescató en 1988 la entrevista a Pombo, Benigno y Urbano que ya había sido divulgada en la década anterior, que conformaba el testimonio de tres cubanos sobrevivientes de la guerrilla del Che en Bolivia. Como ya se ha tratado, en ella relataban la situación que vivieron en las semanas anteriores a los combates en La Higuera, lugar donde cayó el Che y el grupo que integraba su destacamento (39). En ese mismo año se publicó el artículo "La Higuera", tomado de una edición especial de la revista Moncada de 1987, firmado por Adys Cupull y Froilán González. Se trata de una crónica de viajes a la zona boliviana donde murió Guevara, en la que se intentaba resaltar la huella dejada por la guerrilla y su comandante en dicho paraje, con casas "humildes y sencillas como sus moradores" (27). Denota nuevamente esa pervivencia del mártir que muere por una causa más alta que su propia vida: “[...] el Yuro es hoy una solemne quebrada donde la heroicidad del Che se ha convertido en un grito de victoria que [...] nadie podrá interrumpir" (30).

Finalmente, a tenor de la lucha armada, Ernesto Guevara era citado en 1986 en el escrito de René Anillo Capote sobre el pensamiento revolucionario de Carlos Fonseca. Según el autor, el fundador del Frente Sandinista de Liberación Nacional (FSLN) tomó las luchas del Che y de Camilo Torres como guías de 
acción, cuando proclamaba la unidad que se daba en el FSLN, "fusil en mano", de "los verdaderos revolucionarios y los verdaderos cristianos" (25). Anillo Capote hacía referencia también al propio Fonseca como mártir -murió en 1976, tres años antes del triunfo de la Revolución Sandinista-, cuestión recurrente en las publicaciones políticas y militantes de la época, como venimos comentando: "Se demuestra una vez más que la muerte en combate de los precursores de una gran causa no termina con la desaparición física [...]. Carlos Fonseca vive en el corazón del pueblo revolucionario que él quiso" (28). ${ }^{19}$ Además, la victoria de la vía revolucionaria en Nicaragua a finales de la década de los setenta había dado un nuevo impulso al discurso de lucha armada que se había divulgado desde Cuba a partir de 1959, centrando la atención en la región centroamericana por parte de la OSPAAAL, particularmente en Guatemala y El Salvador $(\mathrm{H}$. González 74, “Actual” 89).

Respecto al antimperialismo en la última década objeto de análisis, la revista plasmó de nuevo en 1982 fragmentos del Mensaje a la Tricontinental del Che ("Sobre" 142; "Fin" 147) que, como hemos señalado, se había publicado en una edición especial en abril de 1967: "Al enfocar la destrucción del imperialismo, hay que identificar a su cabeza, la que no es otra que los Estados Unidos de Norteamérica" (Guevara, "Sobre" 142). Un año antes, en el número coincidente con el aniversario de la caída en combate del guerrillero, se incluían fragmentos de sus discursos entre 1961 y 1964 -cuando detentaba el cargo de Ministro de Industria de Cuba-, cuyo hilo conductor eran los problemas del mundo subdesarrollado: "Mientras el imperialismo exista, por definición, ejercerá su dominación sobre otros países; esa dominación se llama hoy neocolonialismo" (Guevara, "Fragmentos" 8).

Bajo el título "La filosofía del despojo debe cesar", se difundieron, en los dos monográficos dedicados a su figura en los ochenta, parte de su alocución ante la Conferencia Mundial de Comercio y Desarrollo de la Organización de las Naciones Unidas (ONU) -celebrada en Ginebra el 25 de marzo de 1964. En ella, Guevara hacía un repaso a las condiciones de "explotación" en las que se encontraban los países subdesarrollados y hacía una crítica abierta a las instituciones económicas internacionales y a la desigualdad en los intercambios comerciales a nivel mundial:

19 Un año antes de la publicación de este artículo, Daniel Ortega asumía la presidencia de Nicaragua, aludiendo a Carlos Fonseca como rescatador del programa de Sandino al fundar el FSLN (Anillo Capote 28). Para una reflexión acerca de la evolución ideológica de la Revolución Nicaragüense, véase Ágreda Portero (231). 
[...] debido a la deflación de los precios de las materias primas que exportan y el alza de los precios de los productos manufacturados que importan [...] producto del dominio imperialista sobre la economía interna y los mercados externos de los países dependientes. (Guevara, "La filosofía" 69)

En base a estas cuestiones, el en aquel entonces ministro de Industria cubano exigía ante la ONU un trato "equitativo" en el comercio internacional -que no "igualitario"-, para que "los pueblos explotados" alcanzaran "un nivel de vida aceptable" (71). Solicitaba, asimismo, la implementación de organismos "financieros, crediticios y arancelarios" que reemplazaran los vigentes en aquel momento - que calificaba de "obsoletos" y "condenables" (72)-, aunque advertía que los "imperialistas" no se quedarían cruzados de brazos para mantener el statu quo existente (73).

Firmado por el Che también estaba el artículo "Cuba ¿excepción histórica o vanguardia en la lucha anticolonialista?”, que Tricontinental publicó en 1987, pero se trataba de un texto que la revista Verde Olivo había sacado en abril de 1961, antes de la invasión de Playa Girón. La intención primigenia del escrito, según Childs (610), fue la de dar respuesta a sus críticos, por lo que a principios de los sesenta se dirigió a los partidos comunistas latinoamericanos, cuando afirmaban, "al igual que lo había hecho el PSP"20", que las condiciones "no eran las adecuadas para la revolución armada". De este modo, la intención de Guevara con el artículo fue la de señalar que Cuba "era solo la primera nación latinoamericana que rompía los moldes comunes de la dependencia económica y la dominación imperialista" (Anderson 478). Señalaba que en la isla se habían dado varios factores excepcionales para el levantamiento: el primero, "esa fuerza telúrica llamada Fidel Castro Ruz", seguido de que "el imperialismo norteamericano estaba desorientado y nunca pudo aquilatar los alcances verdaderos de la Revolución Cubana" y que el campesino cubano se había "proletarizado" por la extensión del "cultivo capitalista", lo que les había dado "una mayor conciencia de clase" (Guevara, "Cuba" 21-22). No obstante, insistía que en el resto de América Latina era posible liberarse "del gran fenómeno del imperialismo con su secuela de gobernantes títeres" y "sus ejércitos mercenarios" (24). Para ello,

20 PSP son las siglas del Partido Socialista Popular de Cuba, el partido comunista del país desde 1944, que en 1961 pasó a formar parte de las Organizaciones Revolucionarias Integradas (ORI), en 1962 se fusionó con el Movimiento 26 de Julio y el Directorio Revolucionario 13 de Marzo formando el Partido Unido de la Revolución Socialista de Cuba (PURSC), hasta la constitución del Partido Comunista Cubano (PCC) en 1965. 
abogaba por la aplicación de la "medicina empírica" que había descubierto: "la posibilidad de la victoria por la vía violenta" (25). Y esa vía pasaba por no abogar por el electoralismo, ${ }^{21}$ ya que, según el Che, si un movimiento popular llegaba al poder a través de las urnas y resolvía acometer grandes transformaciones sociales, ese gobierno podía ser derribado mediante un golpe de estado y "volver a empezar el juego de nunca acabar" (26). La solución armada que proponía también implicaba que esta se desarrollase fuera de las ciudades, ya que en estos escenarios solo sería posible un enfrentamiento "cuando haya un ejército poderoso que lucha contra otro ejército" (28). Esto último se vincula en cierto modo a lo que Childs (613) ha denominado sierraisation del foco, esto es, el proceso por el cual los integrantes de la guerrilla rural ocuparon el lugar más elevado en la concepción guevarista, mientras que el papel de las ciudades pasó a un segundo plano, cuestiones superadas por los movimientos armados que siguieron la estela cubana.

Respecto a piezas de corte antimperialista en las que Guevara era citado en los ochenta por Tricontinental, estaba en primer lugar el pronunciamiento formulado por Maurice Bishop, primer ministro de Granada, en el acto del 1 de mayo de 1980 en la Plaza de la Revolución de La Habana. Sus palabras eran elogiosas para con Cuba y la solidaridad militante, una unidad que, en sus palabras, hacía "temblar al imperialismo" (99). Continuaba haciendo un llamado a la acción por el derecho de la autodeterminación de todos los pueblos para que de este modo se pudiera poner fin a las interferencias extranjeras, a las invasiones y "a las masacres y a los asesinatos de nuestros Sandinos, de nuestros Ches y de nuestros Allendes" (102), poniendo así nombres propios y el guiño de posteridad a los muertos por la causa.

Ese mismo año, la OSPAAAL arribaba a su $15^{\circ}$ aniversario, por lo que en el no. 73 de su órgano incluyó un artículo que hacía un breve recuento de ese tiempo. Guevara era recordado en estas líneas como "heroico ejemplo", "modelo por excelencia del más íntegro revolucionario" y "hombre de ideas claras y profundas capaz de llevar hasta las últimas consecuencias sus convicciones", además de calificar su mensaje a la Tricontinental como "uno de los documentos más lúcidos de nuestra época" (Delgado 13-15). En esta línea estaba el texto de Vo Nguyen Giap, vicepresidente del Consejo de Ministros de Vietnam, que

21 Guevara planteaba en los primeros sesenta el debate mantenido por la izquierda latinoamericana a partir de la fecha: por un lado, los grupos que abogaban por las armas, que se autodenominaron izquierda revolucionaria, y, del otro, el resto de la izquierda, a la que tildaban de reformista por apostar por la vía electoral. Esta era defendida por la mayoría de los partidos comunistas vinculados a la Unión Soviética (Harnecker 24). 
describía al Che como "gran ejemplo de heroísmo revolucionario" (105) para combatir el imperialismo y otorgarle la victoria a "la independencia, la libertad y el progreso social" (106).

En 1983, para conmemorar el 55 natalicio de Ernesto Guevara, Tricontinental incluyó un texto de Salvador Cayetano Carpio, el comandante Marcial, primer responsable de las Fuerzas Populares de Liberación (FLP) Farabundo Martí y miembro de la comandancia general del Frente Farabundo Martí para la Liberación Nacional (FMLN) de El Salvador. ${ }^{22}$ En él hacía hincapié en que "la historia de nuestra América agiganta las enseñanzas y el ejemplo del querido comandante Ernesto Che Guevara", señalando su internacionalismo y su lucha contra el imperialismo (58). Ya en 1987 la revista ofrecía un artículo acerca del papel del Che en la política exterior de la Revolución Cubana, en el que se decía que sus posiciones partían del "derecho conquistado por Cuba" para ocupar un puesto de avanzada en la lucha antimperialista a escala continental y mundial:

Al estudiar la riqueza de contenido del pensamiento de Che, referido al aspecto internacional, se perfilan las premisas fundamentales estratégicas de nuestra política exterior, es decir, su orientación hacia el socialismo y la aplicación consecuente del internacionalismo proletario, como uno de los modos esenciales de contribuir a la victoria sobre el capitalismo. (Ariet 55)

Finalmente, ese mismo año Athos Fava, secretario general del Partido Comunista de Argentina, escribió especialmente para Tricontinental el artículo "Che y los argentinos" con motivo del XX aniversario de la muerte de su compatriota. Se trataba de un análisis de la significación de su figura entre sus coterráneos y de los frustrados intentos por silenciar su memoria en el país. Además, examinaba los errores cometidos por el partido y cómo, a partir de las enseñanzas de Guevara, la organización adoptó una nueva estrategia dirigida a alcanzar, con la unidad de todas las fuerzas revolucionarias y con la solidaridad continental, la segunda y definitiva independencia nacional (31).

22 En ese año 1983 Marcial se suicidó tras haber sido acusado de ser el autor intelectual del asesinato de la comandante Ana María (Morales Carbonell 20). 


\section{A MODO DE CONCLUSIÓN}

En palabras de Martínez Heredia (1171), el asunto central del pensamiento político de Ernesto Che Guevara es "la revolución mundial contra el capitalismo y por el socialismo, desde el mundo neocolonial y colonial”, aunque condicionado "por sus prácticas y por la política cubana en la que milita". En esencia, son las cuestiones principales que, como hemos visto, se reflejan en las páginas de la revista Tricontinental entre 1967 y 1990 respecto del guerrillero argentino. Su experiencia en el Ejército Rebelde de Sierra Maestra y su posterior desempeño político en el gobierno revolucionario de Cuba fueron las facetas que generaron sus obras, artículos y discursos que la revista objeto de estudio intentó plasmar casi en su totalidad a lo largo de más de dos décadas.

El órgano de la OSPAAAL mantuvo de forma constante la figura del Che tanto a través de imágenes como de textos, perpetuando ese legado del que hablan algunos autores, un legado construido esencialmente desde Cuba y desde la propia organización, a tenor de la autoría que reflejan los artículos, las portadas y las imágenes que versan sobre el comandante.

El análisis realizado también nos señala que las piezas que trataban sobre su persona y las de su propia autoría eran las que gozaban de mayor espacio en las páginas de Tricontinental, siendo muchas de ellas tomadas de otras publicaciones cubanas. Esto es indicativo del trasvase existente entre la producción editorial de la isla y de la voluntad de internacionalización de las ideas contenidas en ella. Por este motivo, en el apartado de difusión, la centralidad cubana dentro de la Nueva Izquierda queda patente y, en este caso, con la creación propia de un imaginario alrededor de Guevara.

Tomando el antimperialismo y la lucha armada como temáticas principales, las inserciones sobre el guerrillero argentino dejan la impronta del "icono de un sacrifico testimonial" (Pipitone 324), del "revolucionario sin par" (Anderson 442), del mártir y del ejemplo a seguir, en la línea del lema "Che vive":23

Hay un recuerdo. Desde millares de fotos, pósters, camisetas, cintas, discos, vídeos, postales, retratos, revistas, libros, frases, testimonios, fantasmas todos de la sociedad industrial que no sabe depositar sus mitos en la sobriedad de la memoria, el Che nos vigila. Más imagen con la impresión del póster con la leyenda "Il Che vive", que "sería un auténtico bestseller que vendería un millón de copias” (Moroni y Balestrini 194). 
allá de toda parafernalia retorna. En era de naufragios es nuestro santo laico. Casi 30 años después de su muerte, su imagen cruza las generaciones, su mito pasa correteando en medio de los delirios de grandeza del neoliberalismo. Irreverente, burlón, terco, moralmente terco, inolvidable. (Taibo II 761)

Por tanto, Tricontinental ejerció el papel de "crear dos, tres, muchos Che" en términos de una pervivencia legendaria, tomando su imagen y sus escritos como paradigma a seguir por la izquierda internacional, como así lo constatan los artículos que versaban sobre él o que era citado. De hecho, a pesar de las críticas que el propio guerrillero vertió en la década de 1960 hacia los partidos comunistas por desechar la vía armada como proceso de cambio, a finales de los ochenta, como hemos visto, tenemos el ejemplo del PC argentino, que mostraba su admiración y su respeto por el accionar de su compatriota en las páginas de la revista objeto de estudio. El órgano de la OSPAAAL también dejó constancia de cómo diferentes líderes de movimientos revolucionarios, independentistas y anticolonialistas abogaban por las enseñanzas transmitidas por Guevara, de militancia proletaria internacional, de lucha contra el imperialismo, de la operatividad guerrillera o de los incentivos morales por encima de los materiales.

Todo este conjunto de elementos acerca de Ernesto Che Guevara difundidos por la revista reveló una impronta de tesón divulgador en la etapa en la que se concentra el presente análisis, con más silencios en la década de los setenta provocados por la coyuntura de la política exterior cubana. La cultura revolucionaria difundida desde la isla a partir de 1959 se enmarcaba en los principios del internacionalismo y la lucha en el Tercer Mundo, la independencia y soberanía de cada pueblo, un socialismo independiente del soviético y la resistencia armada contra el imperialismo, cuestiones ampliamente abordadas por Guevara. Esta suerte de identidad colectiva se pudo ver, por un lado, en pueblos, países y gobiernos como el argelino de Ben Bella y, por otro, en guerrillas y grupos armados alrededor del mundo. No obstante, la conformación de una imagen de Cuba como aliado internacionalista, dispuesto a proporcionar armas, financiación e instrucción sin depender de las lógicas de la Guerra Fría, se alteró en el imaginario colectivo tras el fracaso de la guerra de guerrillas y la muerte del Che en 1967, el apoyo cubano a la invasión de Checoslovaquia en 1968 y el alineamiento económico con la URSS en 1970 (Bermello 83-84). De todos modos, la representación modélica y edificante de Guevara se mantuvo y esa simbiosis programática, cultural y política entre Cuba y su "guerrillero heroico" impregnó el discurso emanado desde la isla, 
tiñendo manifiestos, proclamas, acciones y pensamientos a nivel internacional. Y, como hemos visto, la revista Tricontinental fue uno de los canales que sirvió para expandir ese mensaje.

Este estudio abre así la puerta a la perspectiva comparada, con la proyección de futuro de encontrar el rastro del Che en las demás revistas políticas de la época vinculadas a la Nueva Izquierda. Con ello, se podrá trazar un mapa transnacional de la difusión de la ideología revolucionaria guevarista, con el doble objetivo de desentrañar las redes culturales que unían los movimientos alrededor del mundo dentro de la oleada de violencia política y contribuir a la caracterización de la dimensión pública que salía de Cuba hasta la década de 1990.

\section{REFERENCIAS BIBLIOGRÁFICAS}

Abreu Generoso, Lídia María de. "Impulsar la solidaridad activa y revolucionaria': o projeto editorial da revista Tricontinental". Escrituras en tránsito. Revistas y redes culturales en América Latina, editado por César Zamorano Díaz, Ed. Cuarto Propio, 2018.

“Actual de la violencia en Guatemala". Tricontinental, no. 66, 1979, pp. 89-110. Ágreda Portero, José Manuel. “¿Sandino sandinista? Una aproximación a la evolución ideológica de la Revolución Nicaragüense (1926-1979)". Discursos e ideologías de derechas e izquierdas en América Latina y Europa, coordinado por Patricia Calvo González, Universidade de Santiago de Compostela, 2015, pp. 231-248.

Aguirre, Mirta. "Canción antigua a Che Guevara". Tricontinental, no. 83, 1982, p. 12.

“Al lector". Tricontinental, no. 2, 1967, pp. 3-4.

“Al lector". Tricontinental, no. 26, 1971, pp. 2-3.

Anderson, Jon Lee. Che Guevara. Una vida revolucionaria. Anagrama, 2006.

Ariet García, María del Carmen. "El papel de Che en la política exterior de la Revolución Cubana". Tricontinental, no. 113, 1987, pp. 54-59.

Arismedi, Rodney. "América Latina: crisis de la política imperialista". Tricontinental, no. 53, 1977, pp. 83-112.

Artaraz, Kepa. Cuba y la Nueva Izquierda. Una relación que marcó los años 60. Capital Intelectual, 2011.

Barnet, Miguel. "Poema". Tricontinental, no. 83, 1982, p. 29. 
Bermello Corominas, Xaquín. Revolución, esquerda armada e Terceiro Mundo. As experiencias transnacionais da revolución cubana en África: os casos do PAIGC, MPLA e FRELIMO. Trabajo de Fin de Máster, Universidade de Santiago de Compostela, 2019.

Bishop, Maurice. "Lo que hoy hace temblar al imperialismo". Tricontinental, no. 71,1980 , pp. $98-102$.

"Black Panthers: el reto de los afroamericanos. George Murray y Joudon Major Ford". Tricontinental, no. 10, 1969, pp. 96-110.

Calvo González, Patricia. "Spreading the Cuban Revolution through Tricontinental Journal on its First Decade (1967-1977)". Building the Radical Identity. The Diffusion of the Ideological Framework of the New Left. Editores Eduardo Rey Tristán y Alberto Martín Álvarez, Peter Lang, 2021 (en prensa).

Camacho, Fernando y Eugenia Palieraki. "Hasta Siempre, OSPAAAL!". NACLA Report on the Americas, no. 51:4, 2019, pp. 410-421.

Carpio, Salvador Cayetano. "La marcha de la historia en América Latina le está dando la razón”. Tricontinental, no. 87, 1983, pp. 55-58.

Casamitjana, Santiago. "La bella muerte: la representación heroica en las revistas de ERP y Montoneros (1972-1976)". IV Jornadas de Jóvenes Investigadores del Centro de Estudios Históricos, Universidad Nacional de Mar del Plata, 2020, pp. 13-24.

Castro, Fidel. "El Che: aliento universal de lucha". Tricontinental, no. 8, 1968, pp. 97-113.

-----. “Unión sin confines". Tricontinental, no. 25, 1971, pp. 8-29.

----- "Una introducción necesaria". Tricontinental, no. 83, 1982, pp. 126-128.

-----. "Che y su ejemplo". Tricontinental, no. 83, 1982, p. 138.

Cervantes, Lourdes: "La OSPAAAL es un patrimonio del Tercer Mundo". La Revolución Cubana en Nuestra América: el internacionalismo anónimo, editado por Luis Suárez y Dirk Kruijt, Ruth Casa Editorial, 2015, pp. 730-748.

Childs, Matt D. "An Historical Critique of the Emergence and Evolution of Ernesto Che Guevara's Foco Theory". Journal of Latin American Studies, vol. 27, no. 3, October 1995, pp. 593-624. https://doi.org/10.1017/S0022216X00011627

CIA. "The Bolivian Guerrilla Movement: An Interim Assessment”. Intelligence Memorandum, 8 agosto 1967, no. 1374/67, https://www.cia.gov/library/readingroom/ 
-----. "Political Trends in Cuba". Weekly Summary Special Report, 15 marzo 1968, no. 0011/68A, https://www.cia.gov/library/readingroom/

Cortázar, Julio. "Yo tuve un hermano". Tricontinental, no. 83, 1982, p. 54.

Cupull, Adys y Froilán González. "La Higuera”. Tricontinental, no. 119, 1988, pp. 26-30.

"Declaración de la Conferencia de los Partidos Comunistas de América Latina y del Caribe". Tricontinental, no. 44, 1975, pp. 69-108.

Delgado, Eduardo. "Quince años de solidaridad Tricontinental". Tricontinental, no. 73, 1980, pp. 6-16.

Domínguez, Jorge I. La política exterior de Cuba (1962-2009). Ed. Colibrí, 2009. "Editorial". Tricontinental, no. 1, 1967, pp. 1-2.

Estrada, Ulises. "Prólogo". Rebelión Tricontinental. Las voces de los condenados de la tierra de Africa, Asia y América Latina, Ocean Press, 2006, pp. 1-4.

Fava, Athos. "Che y los argentinos". Tricontinental, no. 114, 1987, pp. 25-32.

Feliú Miranda, Santiago R. "El Che en las páginas de la revista Tricontinental". Tricontinental, no. 174, 2012, pp. 5-6.

Fernández G., Manuel. "Los intelectuales de izquierda y la construcción de un imaginario revolucionario para Chile y América Latina. La revista Punto Final entre 1965-1973". Tiempo Histórico, no. 2, 2011, pp. 65-84. https://doi.org/10.25074/th.v0i2.158

Ferreiro, Celso Emilio. "Nana para el Che Guevara". Tricontinental, no. 83, 1982, p. 136.

Fornet, Jorge. El 71. Anatomía de una crisis. Ed. Letras Cubanas, 2013.

Frick, Richard y Ulises Estrada. El cartel tricontinental de solidaridad. Commedia-Verlag, 2003.

FSLN. "Programa del Frente Sandinista de Liberación Nacional". Tricontinental, no. 17,1970 , pp. 61-68.

Gilman, Claudia. Entre la pluma y el fusil. Debates y dilemas del escritor revolucionario en América Latina. Siglo Veintiuno Editores, 2012.

Givan, Rebeca K., Kenneth M. Roberts y Sarah A. Soule. "Introduction. The Dimensions of Diffusion". The Diffusion of Social Movements. Actors, Mechanisms, and Political Effects, editado por Rebeca K. Givan, Kenneth M. Roberts y Sarah A. Soule, Cambridge University Press, 2010, pp. 1-15. https://doi.org/10.1017/CBO9780511761638

González, Humberto. "Antecedentes de la lucha popular en El Salvador". Tricontinental, no. 66, 1979, pp. 73-87. 
González Bermejo, Ernesto. "El vado de la traición". Tricontinental, no. 26, 1971, pp. 63-88.

Gott, Richard. Las guerrillas en América Latina. s. 1., Editorial Universitaria, 1971.

Gracia Santos, Guillermo. Aprendiendo de ellos. Los procesos de difusión político-ideológica transnacional: MLN-Tupamaros y Brigadas Rojas. Tesis doctoral, Universidade de Santiago de Compostela, 2018.

Gracia Santos, Guillermo, y Eduardo Rey Tristán. "L'ultimo progetto di Che Guevara: America Latina". Il Che vive! Ernesto e l'America Latina nel patrimonio della Fondazione Giangiacomo Feltrinelli, Fondazione Giangiacomo Feltrinelli, 2017, pp. 31-45

Grenat, Stella. "El Príncipe Armado. El estudio de la Tricontinental y la OLAS en América Latina: una tarea pendiente". Intellèctus, no. 1, 2020, pp. 287-317.

Guevara, Ernesto. "El Socialismo y el Hombre en Cuba". Marcha, 12/03/1965, pp. 14-15.

-----. "Mensaje a la Tricontinental. Crear dos, tres... muchos Viet-Nam, es la consigna". Tricontinental, suplemento especial, 1967.

-----. "Internacionalismo y antimperialismo". Tricontinental, no. 2, 1967, pp. 19-30.

-----. "El papel que nos corresponde". Tricontinental, no. 8, 1968, pp. 17-34.

-----. "Instrucciones para los cuadros destinados al trabajo urbano". Tricontinental, no. 8, 1968, pp. 93-96.

-----. "Fragmentos de discursos". Tricontinental, no. 78, 1981, pp. 5-10.

-----. "Guerra de Guerrillas: un método". Tricontinental, no. 83, 1982, pp. 42-53.

-----. “¿Qué es un cuadro?”. Tricontinental, no. 83, 1982, pp. 62-63.

-----. “La filosofía del despojo debe cesar". Tricontinental no. 83, 1982, pp. 6473; no. 113, 1987, pp. 34-41.

----. "El Patojo". Tricontinental, no. 83, 1982, pp. 90-93; no. 115, 1988, pp. 17-19.

-----. "Sobre el imperialismo". Tricontinental, no. 83, 1982, p. 142.

-----. "Fin del Mensaje a la Tricontinental”. Tricontinental, no. 83, 1982, p. 147.

-----. "Cuba: ¿excepción histórica o vanguardia en la lucha anticolonialista?". Tricontinental, no. 113, 1987, pp. 20-29.

-----. "El cuadro, columna vertebral de la revolución". Tricontinental, no. 113, 1987, pp. 30-33. 
Guillén, Nicolás. "Che Comandante”. Tricontinental, no. 83, 1982, pp. 144-145; no. 113, 1987, p. 53.

Harnecker, Marta. La izquierda en el umbral del siglo XXI. 2a ed., Ed. Ciencias Sociales, 2001.

Iglesias, Joel. "Junto al Che". Tricontinental, no. 19-20, 1970, pp. 35-50.

Johansen, Kevin. "Mc Guevara's o Che Donald's". The Nada, Warner Chappell Music, 2001 [canción].

Kapcia, Antoni. Cuba in Revolution. A history since fifties. Reaktion Books, 2008.

Kruijt, Dirk. Cuba and Revolutionary Latin America: An Oral History. Zed Books, 2017.

López, Luis, y Trisha Ziff. Chevolution. Red Envelope Ent, 2008 [documental].

Löwy, Michael. El pensamiento del Che Guevara. Siglo Veintiuno Editores, 1974.

Marighella, Carlos. "Minimanual del guerrillero urbano". Tricontinental, no. 16, 1970, pp. 15-56.

Martín Álvarez, Alberto y Eduardo Rey Tristán. "La dimensión transnacional de la izquierda armada". América Latina Hoy, vol. 80, 2018, pp. 9-28. https://doi.org/10.14201/alh201880928

Mármol, Farabundo M. “¿Por qué el FMNL gana la guerra en El Salvador?” (entrevista a Ramiro Vázquez y Pablo Molina). Tricontinental, no. 95, 1984, pp. 4-13.

Martínez Heredia, Fernando. "El pensamiento de Ernesto Che Guevara". Pensar en tiempo de Revolución: antología esencial. Comp. Magdiel Sánchez Quiróz. CLACSO, 2018, pp. 1165-1174. https://doi.org/10.2307/j.ctvn96gc8

Martínez Victores, Ricardo. “7RR. La historia de Radio Rebelde”. Tricontinental, no. 59, 1978, pp. 80-118.

Montes, César y Marco Antonio Yon Sosa. "Guatemala: Comunicado Conjunto de las Fuerzas Armadas Rebeldes y el Movimiento Revolucionario 13 de Noviembre". Tricontinental, no 4-5, 1968, pp. 75-78.

Morales Campos, Reinaldo. "El Che en carteles de la OSPAAAL". América Latina en Movimiento, 2010, https://www.alainet.org/es/active/42247

-----. "45 años haciendo historia, defendiendo cultura y expresando solidaridad. Tributo a la revista Tricontinental". América Latina en Movimiento, 2012, https://www.alainet.org/es/active/53379 
Morales Carbonell, José Antonio. "El suicidio de Marcial ¿Un asunto concluido?”. Nuestras montañas son las masas, Salvador Cayetano Carpio, CEDEMA, pp. 20-67, http://www.cedema.org/uploads/Marcial_Nuestras.pdf

Moro, Lucia. La Tricontinental, una rivista per la revoluzione. Tesi di laurea, Dipartimento di Storia, Università degli Studi di Padova (Italy), 2011.

Moroni, Primo y Nanni Balestrini. La horda de oro (1968-1977). La gran ola revolucionaria y creativa, política y existencial. Traficantes de Sueños, 2006.

Núñez, Carlos. "Los tupamaros: vanguardia armada en Uruguay". Tricontinental, no. 10, 1969, pp. 43-66.

Peredo, Inti. "El Yuro". Tricontinental, no. 83, 1982, pp. 131-133; no. 113, 1987, pp. 48-51.

Pérez Galdós Ortiz, Víctor. "Los poemas de Nicolás Guillén dedicados al Che Guevara". Radio Rebelde, http://www.radiorebelde.cu/che/artes/che nicolas-guillen.html

Pipitone, Ugo. La esperanza y el delirio. Una historia de la izquierda en América Latina. Taurus, 2015.

Pombo, Benigno y Urbano. "La Quebrada del Yuro: recuerdos de un combate". Tricontinental, no. 19-20, 1970, pp. 107-124; no. 117, 1988, pp. 38-50.

Portal Jiménez, Marcelo. "El marxismo en la revista Cuba Socialista en la década del sesenta". Islas, vol. 42, no. 124, 2000, pp. 140-147.

Prensa Latina. “iEnvió el comandante Ernesto 'Che' Guevara transcendental artículo para la revista Tricontinental! Desde algún lugar del mundo", no. 1499, Praga, martes 18 abril 1967, p. 1.

-----. "Texto del artículo enviado desde algún lugar del mundo por el comandante Ernesto 'Che' Guevara para la revista Tricontinental", no. 1500, Praga, miércoles 19 abril 1967, pp. 1-12

Rapoport, David C. "Reflections on the Third or New Left Wave. 17 Years Later". Revolutionary Violence and the New Left. Transnational Perspectives. Editores Alberto Martín Álvarez y Eduardo Rey Tristán, Routledge, 2017, pp. 24-64. https://doi.org/10.4324/9781315645223

Rey Tristán, Eduardo, y Alberto Martín Álvarez. Building the Radical Identity. The Diffusion of the Ideological Framework of the New Left. Peter Lang, 2021 (en prensa).

Rodríguez Bermúdez, Jorge. "Un cartel para tres continentes", Tricontinental, no. 133,1996 , pp. 32-37. 
Rodríguez Herrera, Mariano. "Con la adarga al brazo", Tricontinental, no. 44, 1975, pp. 123-135.

Seleme, Susana. "Bolivia o el coraje de un pueblo". Tricontinental, no. 41, 1974, pp. 16-53.

Suárez, Luis: "Prefacio". Rebelión Tricontinental. Las voces de los condenados de la tierra de África, Asia y América Latina. Ocean Press, pp. 5-11.

Sung, Kim Il. "La gran causa revolucionaria antimperialista de los pueblos de Asia, África y América Latina es invencible”. Tricontinental, no. 8, 1968, pp. 6-16.

Taibo II, Paco Ignacio. Ernesto Guevara, también conocido como el Che. Planeta, 1997.

“Uruguay: los Tupamaros en acción”. Tricontinental, no. 17, pp. 45-60. 